\title{
Asymptomatic only at first sight: malaria infection among schoolchildren in highland Rwanda
}

\author{
Kevin C. Sifft', Dominik Geus ${ }^{1}$, Caritas Mukampunga ${ }^{2}$, Jean Claude Mugisha², Felix Habarugira ${ }^{2}$, \\ Kira Fraundorfer ${ }^{3}$, Claude Bayingana ${ }^{2}$, Jules Ndoli ${ }^{2}$, Irenee Umulisa ${ }^{4}$, Corine Karema ${ }^{4,5,6}$, \\ George von Samson-Himmelstjerna ${ }^{3}$, Toni Aebischer ${ }^{7}$, Peter Martus ${ }^{8}$, Augustin Sendegeya ${ }^{2}$, \\ Jean Bosco Gahutu² and Frank P. Mockenhaupt ${ }^{1^{*}}$
}

\begin{abstract}
Background: Plasmodium infection and malaria in school children are increasingly recognized as a relevant public health problem, but data on actual prevalence and health consequences are insufficient. The present study from highland southern Rwanda aimed at estimating infection prevalence among children attending school, at identifying associated factors and at assessing the clinical consequences of these infections.

Methods: In a survey including 12 schools in the Huye district of Rwanda, 1089 children aged 6-10 years were clinically and anthropometrically examined, malaria parasites were diagnosed by microscopy and PCR, haemoglobin concentrations were measured, and socio-economic and behavioural parameters as well as medical histories were obtained.

Results: Upon examination, the vast majority of children was asymptomatic (fever $2.7 \%$ ). Plasmodium infection was detected in 22.4\% (Plasmodium falciparum, 18.8\%); $41 \%$ of these were submicroscopic. Independent predictors of infection included low altitude, higher age, preceding antimalarial treatment, and absence of electricity or a bicycle in the household. Plasmodium infection was associated with anaemia (mean haemoglobin difference of $-1.2 \mathrm{~g} / \mathrm{dL}$; $95 \% \mathrm{Cl},-0.8$ to $-1.5 \mathrm{~g} / \mathrm{dL}$ ), fever, underweight, clinically assessed malnutrition and histories of fever, tiredness, weakness, poor appetite, abdominal pain, and vomiting. With the exception of underweight, these conditions were also increased at submicroscopic infection.
\end{abstract}

Conclusion: Malaria infection is frequent among children attending school in southern highland Rwanda. Although seemingly asymptomatic in the vast majority of cases, infection is associated with a number of non-specific symptoms in the children's histories, in addition to the impact on anaemia. This argues for improved malaria surveillance and control activities among school children.

\section{Background}

Plasmodium infection can cause a wide variety of illnesses, ranging from asymptomatic infection over uncomplicated malaria to severe and complicated disease [1-4]. Owing to the enormous morbidity and mortality of clinical malaria in young children, the epidemiology

\footnotetext{
*Correspondence: frank.mockenhaupt@charite.de

${ }^{1}$ Institute of Tropical Medicine and International Health, Charité-

University Medicine Berlin, Berlin, Germany

Full list of author information is available at the end of the article
}

and consequences of asymptomatic infection in different settings and age-groups has received comparatively little attention. Increasingly, however, the underrated impact of asymptomatic and/or submicroscopic infections is now being recognized $[2,3,5-10]$.

Partial immunity against malaria develops during childhood in endemic regions as a result of repeated exposure. Increasing age has consequently been associated with low and submicroscopic parasite density as well as with asymptomatic infection, particularly among 
school-age children [5, 11-14]. Most of these infections remain undiagnosed and untreated $[14,15]$, and-in the case of schoolchildren-are not subject of targeted interventions. However, the significance of these asymptomatic Plasmodium infections is likely underestimated as they contribute to inflammatory responses, anaemia, cognitive impairment and delayed physical development $[5,9,10,15-20]$. Moreover, submicroscopic infections tend to persist for longer than symptomatic ones [13, 21], thereby constituting a sizeable transmission reservoir $[2,3,14]$. This has particular importance in areas of low endemicity considering the increase of submicroscopic (and frequently asymptomatic and untreated) infections with declining malaria transmission $[2,3,11,21]$.

In Rwanda, comprehensive malaria control measures since 2005 have been paralleled by $50 \%$ or higher declines in malaria morbidity and mortality [22]. In 2010, in the southern highland Huye district, PCRassessed Plasmodium prevalence among rural children under 5 years of age was $16 \%$, the majority of infections being asymptomatic [18]. This area represents a hypoto meso-endemic setting as seen in many other parts of the country [12]. No data, however, is available as to the epidemiological characteristics and effects of seemingly asymptomatic and/or submicroscopic Plasmodium infections among school-age children living in the highlands of Rwanda. Such knowledge, nevertheless, forms the prerequisites for the design of targeted interventions, the reduction of transmission reservoirs, and, ultimately, elimination.

In 2014, children attending primary schools in the largely rural Huye district of highland southern Rwanda were recruited for a study on anthelminthic treatment efficacy. Based on this study population, the present analysis aimed at estimating the prevalence of Plasmodium infection including submicroscopic ones, at identifying socio-demographic and -economic as well as behavioural factors associated with infection, and at assessing the clinical manifestation of these infections with particular focus on anaemia and non-specific symptoms.

\section{Methods}

\section{Study design, setting and population}

This observational, cross-sectional study was conducted in October 2014 in the Huye district, Southern Province, Rwanda. Huye district (population 330,000) is located on Rwanda's central plateau, which is characterized by an average altitude of $1600-1800 \mathrm{~m}$, a mean temperature of $19{ }^{\circ} \mathrm{C}$ and a yearly rainfall of approximately $1200 \mathrm{~mm}$ with two rainy seasons (October-December; MarchMay). Malaria transmission in the area is perennial but low with peaks during the rainy seasons. Plasmodium falciparum is the predominant species [12, 18, 23].
Huye district is subdivided into 14 sectors (sub-districts; see Fig. 1). For each sector, one primary school of 500-1100 pupils was randomly selected from the district's school list. Two schools could not be accessed later on, leaving a sample of 12 schools located at altitudes between 1560 and $1850 \mathrm{~m}$. At each school, 150 children aged 6-10 years were randomly selected from the school list aiming at a number of 100 participants per school to be recruited. Several days before examination, meetings were held at each school to explain purpose and procedures of the study to teachers and parents. Permissions were obtained from school directors, heads of local health centres and the district health office. Written informed consent and assent were obtained from the parents and the children, respectively. The study protocol was approved by the Rwandan National Ethics Committee (242/RNEC/2014), and the Rwandan Ministry of Education granted permission to conduct the study (2543/12.00/2014).

\section{Examinations and laboratory procedures}

Alongside routine deworming activities, all participating schools were visited within one week in October 2014. Attending children were clinically examined, and axillary temperature was measured. A brief medical history was obtained from the children, and results were combined with the history as stated by the parents upon interviewing (see below). Age, sex, weight, height, midupper arm circumference (MUAC), and fever (axillary temperature $\geq 37.5{ }^{\circ} \mathrm{C}$ ) were documented. Weight-forage $\mathrm{z}$ (WAZ) scores and height-for-age $\mathrm{z}$ (HAZ) scores were calculated using AnthroPlus [24]. Underweight and stunting were defined as a WAZ or HAZ score $<-2 \mathrm{SD}$, respectively. In addition, clinically assessed malnutrition as determined by the attending physician upon physical examination was documented. Peripheral venous blood was collected into EDTA. Haemoglobin $(\mathrm{Hb})$ concentrations were measured using a HemoCue photometer (Ängelholm, Sweden), and anaemia was defined as a haemoglobin concentration $<12 \mathrm{~g} / \mathrm{dL}$ according to age-related and altitude-adjusted cut-off values [25]. Onsite, $P$. falciparum and non-falciparum malaria parasites were detected by immunochromatographic dipstick tests (SD BIOLINE Malaria Ag P.f/Pan, Standard Diagnostics Inc, Gyeonggi-do, Korea); children found positive were treated with artemether-lumefantrine. In case of further illness upon clinical examination, treatment was provided according to Rwandan treatment guidelines, if needed. Blood samples were transported on wet ice to the central laboratory, University Teaching Hospital of Butare (UTBH). Malaria parasites were counted on Giemsastained thick blood films per 200 white blood cells (WBCs), and parasite density was calculated assuming a 


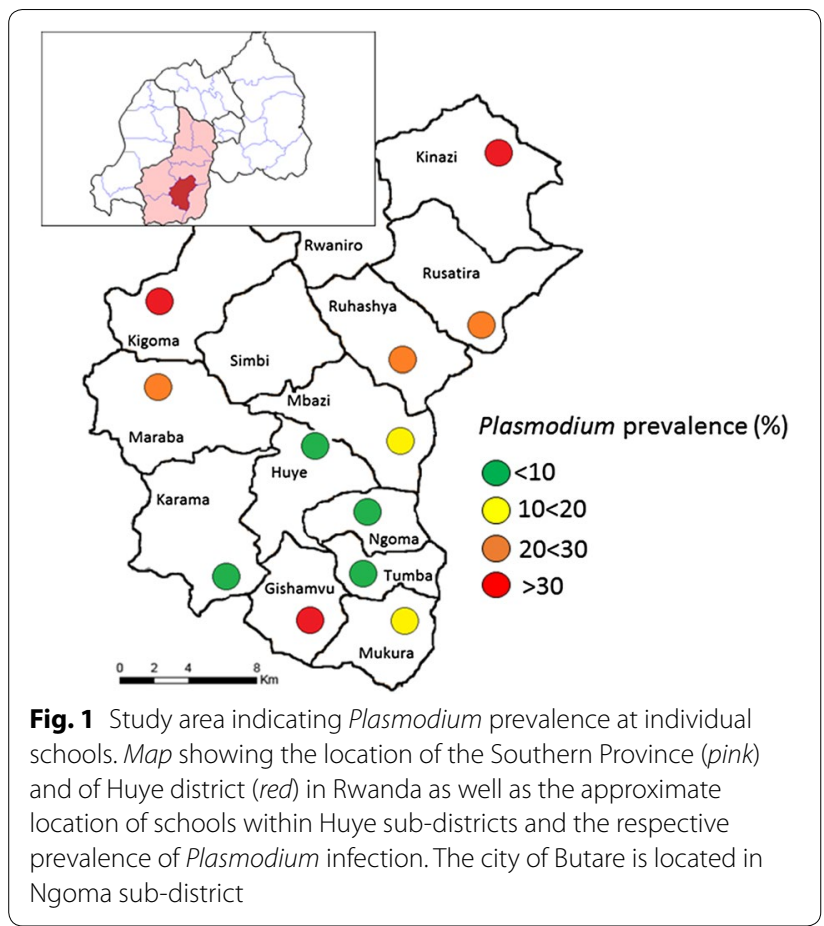

mean WBC count of $8000 / \mu \mathrm{L}$. A slide was declared negative only after having counted 500 WBCs. Malaria was defined as any microscopically visible parasitaemia plus fever or a history of fever within the preceding $48 \mathrm{~h}$. DNA was extracted from stabilized full blood aliquots (AS1 \& Qiamp blood kit; Qiagen, Germany), and Plasmodium species and submicroscopic infections were identified by semi-nested multiplex polymerase chain reaction (PCR) assays [26]. Plasmodium spp. infection was defined as any parasitaemia detected either by microscopy or PCR. Asymptomatic infection herein is defined as the presence of Plasmodium spp. in the absence of fever upon examination. This does not exclude the presence of signs and symptoms in the history of the children.

\section{Socio-economic status and household visits}

Trained health workers visited the households of the recruited children and conducted interviews with parents or guardians using a standardized questionnaire. The questionnaire in the local Kinyarwanda language was largely based on precursors used in previous studies in the region [23]. Data collected included information on paternal education and occupation, household characteristics and assets, ability to pay school and insurance fees, ownership and type of livestock, sanitary facilities, water supply and mosquito net ownership and use as well as illnesses or symptoms the child suffered within the preceding 2 weeks, treatment-seeking, and current or past drug use including anti-malarials.

\section{Statistical analysis}

Data from questionnaires, clinical examination, and laboratory results were double-entered into electronic databases and cross-checked. SPSS (SPSS Statistics Version 23.0, IBM Corp., Armonk, NY, USA) was used for statistical data analysis. Geometric mean parasite densities (GMPDs) and 95\% confidence intervals (95\% CIs) were calculated. Continuous variables were compared between groups by Student's t test, Mann-Whitney or KruskalWallis tests, and proportions by $x^{2}$ test or Fisher's exact test. Odds ratios (ORs) and 95\% CIs were computed. Evaluation of determinants of Plasmodium infection and of clinical symptoms was performed by simple and multiple logistic regression analysis. Analyses were adjusted for intracluster correlations (clusters $=$ schools) by use of generalized estimating equations (GEE, exchangeable correlation structure for subjects within identical villages). Multivariate analysis of factors associated with Plasmodium infection was done for the complete sample using multiple imputation for missing data. Stepwise backward selection was performed, and final models included those factors that retained statistical significance. A $P$ value $<0.05$ was considered statistically significant.

\section{Results}

\section{Study population}

Out of 1182 recruited children, Plasmodium microscopy and PCR results were available for 1089 children. These form the base of the current analysis, and their characteristics are shown in Table 1. Girls slightly predominated. Upon clinical examination the presence of fever was low (2.7\%), and the vast majority of children was clinically unsuspicious; the leading clinical diagnoses were fungal skin infection $(8.8 \%, 95 / 1076)$, dental caries $(3.4 \%$, $37 / 1079)$ and respiratory problems (1.8\%, 19/1066). Underweight and/or stunting affected one in six children; anaemia was seen in one in three children. Based on statements of both children and parents, one-third of the children had a history of abdominal pain in the preceding two weeks, followed by cough and fever. One in five children had attended a health facility within the previous 2 weeks and one in six children had received an antimalarial within the preceding month (Table 2).

Questionnaire data on SES were available for 1019 participants and reflected a generally poor, rural population (Table 2). Parental primary education predominated but $16 \%$ had no formal education at all. The vast majority of children $(83 \%)$ had slept under a bed net the night before the survey but this proportion declined with age to $78 \%$ $(168 / 215)$ among children aged 10 years $(P=0.04$ for comparison across years of age).

Infection with Plasmodium spp. as detected by PCR was present in more than a fifth of all children and was 
Table 1 Characteristics of 1089 Rwandan schoolchildren

\begin{tabular}{|c|c|}
\hline Parameter & Value \\
\hline No. & 1089 \\
\hline Female $(\%, n / n)$ & $54.1(589)$ \\
\hline Age (years; median, range) & $8(6-10)$ \\
\hline Weight (kg; median, range $)^{\mathrm{a}}$ & $21.8(12.0-41.8)$ \\
\hline Height $\left(\mathrm{cm}\right.$; median, range) ${ }^{\mathrm{b}}$ & $121.5(99.5-154.0)$ \\
\hline Weight-for-age Z-score (WAZ; median, range) ${ }^{a}$ & $-1.05(-4.77-2.02)$ \\
\hline Underweight (WAZ $<2 ; \%, \mathrm{n} / \mathrm{n})$ & $16.0(173 / 1080)$ \\
\hline Height-for-age Z-score (HAZ; median, range) ${ }^{b}$ & $-1.06(-4.99-3.14)$ \\
\hline Stunting $(H A Z<2 ; \%, n / n)$ & $17.5(189 / 1079)$ \\
\hline MUAC $(\mathrm{cm} ; \text { mean } \pm \mathrm{SD})^{\mathrm{a}}$ & $16.2 \pm 1.3$ \\
\hline Clinically assessed malnutrition (\%, n/n) & $22.0(238 / 1080)$ \\
\hline Axillary temperature $\left({ }^{\circ} \mathrm{C} ;\right.$ mean $\left.\pm \mathrm{SD}\right)$ & $36.5 \pm 0.54$ \\
\hline Fever $(\%, n / n)$ & $2.7(29 / 1080)$ \\
\hline $\mathrm{Hb}(\mathrm{g} / \mathrm{dL} \text {; median, range })^{\mathrm{a}}$ & $12.5(6.0-16.6)$ \\
\hline Anaemia $(\%, n / n)$ & $36.4(393 / 1079)$ \\
\hline \multicolumn{2}{|l|}{ History in preceding 2 weeks $(\%, n / n)$} \\
\hline Abdominal pain & $34.1(371)$ \\
\hline Cough & $28.2(307)$ \\
\hline Fever & $25.3(276)$ \\
\hline Poor appetite & $19.7(215)$ \\
\hline Weakness & $17.2(178 / 1032)$ \\
\hline Tiredness & $13.9(151)$ \\
\hline Diarrhea & $12.8(139)$ \\
\hline Vomiting & $8.5(93)$ \\
\hline \multicolumn{2}{|l|}{ Plasmodium infection $(\%, \mathrm{n} / \mathrm{n})$} \\
\hline Plasmodium spp. PCR positive & $22.4(244)$ \\
\hline P. falciparum, PCR positive & $18.8(205)$ \\
\hline P. ovale, PCR positive & $4.9(53)$ \\
\hline P. malariae, PCR positive & $0.4(4)$ \\
\hline Plasmodium spp., microscopy positive ${ }^{c}$ & $13.9(151)$ \\
\hline Submicroscopic infection & $9.3(101)$ \\
\hline Geometric mean parasite density $(/ \mu \mathrm{L} ; 95 \% \mathrm{Cl})$ & $2188(1582-3026)$ \\
\hline
\end{tabular}

largely due to P. falciparum (Table 1); $41 \%$ of these infections were submicroscopic, i.e., below the threshold of microscopy but detected by PCR.

\section{Factors associated with Plasmodium infection}

The prevalence of Plasmodium infection ranged from $1.4 \%$ in urban Ngoma sector (city of Butare) to $47 \%$ in the rural Kigoma sector $(P<0.0001$; Fig. 1$)$. This impact was considered by GEE in analysing factors associated with Plasmodium infection (Table 3). In univariate analysis, several factors were associated with reduced odds of infection including increasing altitude, parental secondary or higher education, various household parameters of comparatively higher SES status (high number
Table 2 Selected socio-economic characteristics of 1019 Rwandan schoolchildren

\begin{tabular}{|c|c|}
\hline Parameter & Value \\
\hline No. & 1019 \\
\hline \multicolumn{2}{|l|}{ Maternal education $(\%, n / n)$} \\
\hline None & $19.0(175 / 923)$ \\
\hline Primary & $67.2(620 / 923)$ \\
\hline Secondary or higher; else & $11.1(102 / 923)$ \\
\hline Not ascertainable & $2.8(26 / 923)$ \\
\hline \multicolumn{2}{|l|}{ Paternal education $(\%, \mathrm{n} / \mathrm{n})$} \\
\hline None & $13.4(92 / 685)$ \\
\hline Primary & $62.0(425 / 685)$ \\
\hline Secondary or higher; else & $13.3(91 / 685)$ \\
\hline Not ascertainable & $11.2(77 / 685)$ \\
\hline Mother's occupation farmer or labourer & $93.7(837 / 932)$ \\
\hline Father's occupation farmer or labourer & $93.7(568 / 606)$ \\
\hline No. of people in household (median, range) ${ }^{\mathrm{a}}$ & $6(1-14)$ \\
\hline No. of siblings (median, range) $)^{a}$ & $3(0-10)$ \\
\hline No. of rooms in household (median, range) ${ }^{b}$ & $2(1-9)$ \\
\hline Farmland ownership $(\%, \mathrm{n} / \mathrm{n})$ & $27.1(276 / 1019)$ \\
\hline \multicolumn{2}{|l|}{ Household assets $(\%, n / n)$} \\
\hline Radio & $56.9(577 / 1014)$ \\
\hline Phone & $54.9(556 / 1013)$ \\
\hline Bicycle & $16.1(163 / 1015)$ \\
\hline Electricity & $15.8(161 / 1017)$ \\
\hline Television & $7.6(77 / 1014)$ \\
\hline Fridge & $1.9(19 / 1014)$ \\
\hline Piped water & $13.7(139 / 1011)$ \\
\hline Ability to treat water & $37.0(353 / 953)$ \\
\hline Floor material soil $(\%, n / n)$ & $75.8(766 / 1011)$ \\
\hline Unable to pay school fee $(\%, n / n)$ & $66.5(614 / 923)$ \\
\hline Unable to pay health insurance $(\%, n / n)$ & $51.1(511 / 1000)$ \\
\hline Slept under a bed net last night $(\%, n / n)$ & $82.7(842 / 1018)$ \\
\hline $\begin{array}{l}\text { Attended health facility within last } \\
\text { two weeks }(\%, n / n)\end{array}$ & $21.0(214 / 1019)$ \\
\hline $\begin{array}{l}\text { Received anti-malarial treatment within } \\
\text { last month }(\%, \mathrm{n} / \mathrm{n})\end{array}$ & $16.0(160 / 1000)$ \\
\hline $\begin{array}{l}\text { Time to reach next health centre less } \\
\text { than } 30 \min (\%, n / n)\end{array}$ & $25.1(255 / 1017)$ \\
\hline
\end{tabular}

a $n=1014$

b $n=938$

of rooms; presence of electricity, non-soil floor material, bicycle, TV set, and mobile phone; ability to pay school fees and health insurance; treatment of water prior to drinking). Sleeping under a bed net the night before examination tended to reduce the odds of infection even though the prevalence of microscopically visible parasitaemia was reduced [19.3\% (34/176) vs. $12.8 \%$ (108/841), $P=0.02]$. Positively associated factors were an age of 10 years, stunting, previous health facility attendance or anti-malarial treatment, and a distant health centre. In 
multivariate analysis, an age of 10 years and antimalarial treatment within the previous month were independent predictors of Plasmodium infection whereas increasing altitude, the availability of electricity in the household, and the possession of a bicycle reduced the odds.

Concurrent infection with soil-transmitted helminths (virtually all Ascaris lumbricoides, detected by PCR [27]) was not associated with Plasmodium infection: $22.5 \%$ (72/320) and 20.7\% (124/600) of A. lumbricoides infected and non-infected children, respectively, harboured Plasmodium parasites $(P=0.52)$.

\section{Clinical manifestations of Plasmodium infection}

The vast majority of all children was asymptomatic upon clinical examination even though abdominal pain, cough, fever and other non-specific signs and symptoms were rather common in their histories (see above and Table 1). The influence of Plasmodium infection on signs and symptoms was analysed, further separating into microscopic and submicroscopic infections (Table 4). Plasmodium infection per se was associated with anaemia (mean $\mathrm{Hb}$ difference of $-1.2 \mathrm{~g} / \mathrm{dL}$ ), fever (though in $7.5 \%$ only of those infected), underweight, clinically assessed malnutrition and histories of fever, tiredness, weakness, poor appetite, abdominal pain, and vomiting. At microscopically visible parasitaemia, the presence of these signs and symptoms was generally increased. At submicroscopic infection, anaemia prevalence was almost doubled as compared to uninfected children (mean $\mathrm{Hb}$ difference of $-0.9 \mathrm{~g} / \mathrm{dL}$ ) but current fever was not increased, and no association with nutritional status was present. Still, among children with submicroscopic infections, fever, tiredness, weakness, poor appetite, and vomiting were significantly more frequently reported to have been present within the preceding two weeks than among their uninfected peers. Notably, the proportion of children affected by these conditions did not differ substantially between children with microscopic or submicroscopic infection (Table 4). No association of Plasmodium infection with diarrhoea or cough was observed.

Separating into mono-infections with $P$. falciparum and $P$. ovale, no significant differences with respect to the clinical manifestation were observed. One notable exception was anaemia, which tended to be more common among $P$. falciparum infected children $(62.5 \%, 115 / 184)$ as compared to their $P$. ovale infected peers $(45.7 \%$, $19 / 35 ; P=0.06$ ).

\section{Discussion}

In this cross-sectional survey among largely afebrile children attending school in southern Rwanda, 22\% were infected with Plasmodium spp., predominantly $P$. falciparum, and $41 \%$ of these infections were submicroscopic.
Infection was predicted by older age, low altitude, previous treatment, and absence of electricity or bicycle. Despite its ostensibly asymptomatic presentation, infection was associated with anaemia, underweight, and a number of non-specific symptoms in the children's histories.

Infection prevalence varied greatly between locations, with a tendency of decline closer to the city of Butare (located in Ngoma sector, Fig. 1). Such variation is considered to reflect multiple and geographically diverse factors including altitude, rainfall, topography, land use, SES and health-seeking behaviour [28]. Among these, altitude was the strongest predictor of infection in the present study. Declining infection prevalence with increasing altitude is a common pattern also in neighbouring countries $[8,28-31]$. For example, in Tanzanian children, infection prevalence declined by $5-21 \%$ for every $100-\mathrm{m}$ increase in altitude $[28,30]$. The extent of this effect even on a small range between 1560 and $1850 \mathrm{~m}$ in the present study is remarkable. The higher prevalence of Plasmodium infection at lower altitude, i.e., usually at the valley bottoms, is most likely explained by the closer proximity to vector breeding sites in stagnant waters and commonly practiced rice cultivation. In line with that, valley floors in neighbouring Burundi are considered sources of infection at higher altitudes [31]. Of note, the prevalence of Plasmodium infection did not show the usual decline with age, i.e., with cumulative exposure to malaria parasites. This suggests that the intensity of Plasmodium transmission in the study area is insufficient to build up immune responses during childhood, which prevent infection. Likewise, in neighbouring Tanzania, the age-dependent decline of infection prevalence has been found to vanish at an altitude similar to that of the present study area $[28,30]$. In a previous survey in the study area [18], infection prevalence in young community children increased up to the age of $4-5$ years and up to a level of $20-25 \%$, i.e., a prevalence that was seen in most of the children in the present study. Children aged 10 years showed a significantly increased infection prevalence. This may reflect their comparatively lower use of bed nets as well as other behavioural characteristics of older children such as increased exposure due to longer staying outside in the evenings or traveling to areas of higher transmission. Similar to other studies from Rwanda [12, 18, 32], various indicators of low SES associated with Plasmodium infection but in multivariate analysis, only the protective parameters household availability of electricity and of a bicycle (each present in $16 \%)$ remained. While electricity reflects both, increased SES and proximity to rather urban settings [23], the latter may indicate increased access to malaria-related information, improved awareness and increased usage 
Table 3 Univariate and multivariate analysis of factors associated with Plasmodium infection (PCR) among Rwandan schoolchildren

\begin{tabular}{|c|c|c|c|c|c|c|c|c|}
\hline \multirow[t]{2}{*}{ Variable } & \multirow[t]{2}{*}{ No. } & \multirow{2}{*}{$\begin{array}{l}\text { Proportion } \\
\text { infected }(\%, n)\end{array}$} & \multicolumn{3}{|c|}{ Univariate analysis } & \multicolumn{3}{|c|}{ Multivariate analysis } \\
\hline & & & OR & $95 \% \mathrm{Cl}$ & $P$ & aOR & $95 \% \mathrm{Cl}$ & $P$ \\
\hline \multicolumn{9}{|l|}{ Age (years) } \\
\hline 6 & 132 & $20.5(27)$ & 1 & & & 1 & & \\
\hline 7 & 243 & $17.7(43)$ & 0.84 & $0.61-1.15$ & 0.28 & 0.85 & $0.64-1.12$ & 0.25 \\
\hline 8 & 268 & $20.1(54)$ & 0.98 & $0.74-1.31$ & 0.90 & 0.88 & $0.66-1.18$ & 0.40 \\
\hline 9 & 214 & $22.0(47)$ & 1.09 & $0.78-1.53$ & 0.60 & 1.10 & $0.80-1.49$ & 0.56 \\
\hline 10 & 232 & $31.5(73)$ & 1.79 & $1.24-2.57$ & 0.002 & 1.71 & $1.15-2.55$ & 0.008 \\
\hline \multicolumn{9}{|l|}{ Stunting (HAZ < 2SD) } \\
\hline No & 890 & $20.6(183)$ & 1 & & & & & \\
\hline Yes & 189 & $31.2(59)$ & 1.75 & $1.22-2.52$ & 0.002 & - & - & n.s. \\
\hline \multicolumn{9}{|l|}{ Residence altitude (m) } \\
\hline$<1700$ & 410 & $33.7(138)$ & 1 & & & 1 & & \\
\hline $1700-1750$ & 514 & $19.3(99)$ & 0.47 & $0.24-0.93$ & 0.0001 & 0.61 & $0.37-1.02$ & 0.061 \\
\hline$>1750$ & 165 & $4.2(7)$ & 0.09 & $0.03-0.23$ & 0.031 & 0.13 & $0.07-0.23$ & $<0.0001$ \\
\hline \multicolumn{9}{|l|}{ Maternal education } \\
\hline None & 175 & $25.9(47)$ & 1 & & & & & \\
\hline Primary & 620 & $22.9(142)$ & 0.81 & $0.44-1.50$ & 0.50 & - & - & n.s. \\
\hline Secondary/tertiary & 102 & $8.8(9)$ & 0.26 & $0.12-0.61$ & 0.002 & - & - & n.s. \\
\hline \multicolumn{9}{|l|}{ Paternal education } \\
\hline None & 92 & $19.6(18)$ & 1 & & & & & \\
\hline Primary & 425 & $22.4(95)$ & 1.18 & $0.67-2.09$ & 0.56 & - & - & n.s. \\
\hline Secondary/tertiary & 91 & $8.8(9)$ & 0.4 & $0.16-0.97$ & 0.043 & - & - & n.s. \\
\hline \multicolumn{9}{|c|}{ No. of rooms in household } \\
\hline $1-2$ & 575 & $22.4(129)$ & 1 & & & & & \\
\hline $3-4$ & 333 & $26.1(87)$ & 1.22 & $0.79-1.90$ & 0.37 & - & - & n.s. \\
\hline$>4$ & 30 & $3.3(1)$ & 0.12 & $0.03-0.50$ & 0.004 & - & - & n.s. \\
\hline \multicolumn{9}{|c|}{ Electricity in household } \\
\hline No & 856 & $25.8(221)$ & 1 & & & 1 & & \\
\hline Yes & 161 & $5.6(9)$ & 0.17 & $0.06-0.50$ & 0.001 & 0.31 & $0.14-0.69$ & 0.004 \\
\hline \multicolumn{9}{|l|}{ Floor material } \\
\hline Plain soil & 766 & $26.8(205)$ & 1 & & & & & \\
\hline Else & 245 & $10.2(25)$ & 0.31 & $0.18-0.55$ & 0.0001 & - & - & n.s. \\
\hline \multicolumn{9}{|l|}{ Radio in household } \\
\hline No & 437 & $24.9(109)$ & 1 & & & & & \\
\hline Yes & 577 & $20.6(119)$ & 0.78 & $0.55-1.11$ & 0.167 & - & - & n.s. \\
\hline \multicolumn{9}{|l|}{ Bicycle in household } \\
\hline No & 852 & $24.3(207)$ & 1 & & & 1 & & \\
\hline Yes & 163 & $13.5(22)$ & 0.49 & $0.30-0.79$ & 0.004 & 0.51 & $0.30-0.86$ & 0.012 \\
\hline \multicolumn{9}{|l|}{ TV set in household } \\
\hline No & 937 & $24.1(226)$ & 1 & & & & & \\
\hline Yes & 77 & $2.6(2)$ & 0.08 & $0.03-0.26$ & 0.0001 & - & - & n.s. \\
\hline \multicolumn{9}{|c|}{ Mobile phone in household } \\
\hline No & 457 & $28.0(128)$ & 1 & & & & & \\
\hline Yes & 556 & $18.0(100)$ & 0.56 & $0.35-0.91$ & 0.018 & - & - & n.s. \\
\hline \multicolumn{9}{|c|}{ Ability to pay school fees } \\
\hline No & 614 & $26.1(160)$ & 1 & & & & & \\
\hline Yes & 309 & $14.9(46)$ & 0.50 & $0.30-0.81$ & 0.006 & - & - & n.s. \\
\hline
\end{tabular}


Table 3 continued

\begin{tabular}{|c|c|c|c|c|c|c|c|c|}
\hline \multirow[t]{2}{*}{ Variable } & \multirow[t]{2}{*}{ No. } & \multirow{2}{*}{$\begin{array}{l}\text { Proportion } \\
\text { infected }(\%, n)\end{array}$} & \multicolumn{3}{|c|}{ Univariate analysis } & \multicolumn{3}{|c|}{ Multivariate analysis } \\
\hline & & & OR & $95 \% \mathrm{Cl}$ & $P$ & aOR & $95 \% \mathrm{Cl}$ & $P$ \\
\hline \multicolumn{9}{|c|}{ Ability to pay health insurance } \\
\hline No & 511 & $28.4(145)$ & 1 & & & & & \\
\hline Yes & 489 & $16.6(81)$ & 0.50 & $0.33-0.77$ & 0.002 & - & - & n.s. \\
\hline \multicolumn{9}{|c|}{ Water treatment } \\
\hline No & 600 & 26.5 (159) & 1 & & & & & \\
\hline Yes & 353 & $14.4(51)$ & 0.47 & $0.29-0.77$ & 0.003 & - & - & n.s. \\
\hline \multicolumn{9}{|c|}{ Child slept under bed net last night } \\
\hline No & 176 & $30.1(53)$ & 1 & & & & & \\
\hline Yes & 842 & $20.9(176)$ & 0.61 & $0.35-1.07$ & 0.084 & - & - & n.s. \\
\hline \multicolumn{9}{|c|}{ Child attended health facility within preceding 2 weeks } \\
\hline No & 805 & $20.6(166)$ & 1 & & & & & \\
\hline Yes & 214 & $31.8(68)$ & 1.79 & $1.42-2.26$ & 0.0001 & - & - & n.s. \\
\hline \multicolumn{9}{|c|}{ Child received any malaria treatment within preceding month } \\
\hline No & 840 & $17.6(148)$ & 1 & & & 1 & & \\
\hline Yes & 160 & $50.0(80)$ & 4.68 & $2.67-8.19$ & 0.0001 & 3.07 & $1.93-4.89$ & $<0.0001$ \\
\hline \multicolumn{9}{|c|}{ Time to reach next health centre (min) } \\
\hline$<30$ & 255 & $14.9(38)$ & 1 & & & & & \\
\hline$>30$ & 762 & $25.3(193)$ & 1.94 & $0.95-3.93$ & 0.067 & - & - & n.s. \\
\hline
\end{tabular}

OR, odds ratio; $95 \% \mathrm{Cl}, 95 \%$ confidence interval; aOR, adjusted odds ratio, adjusted for all other factors shown in table and taking into account cluster effects

Table 4 Clinical manifestations of Plasmodium spp. infection among 1071 Rwandan schoolchildren

\begin{tabular}{|c|c|c|c|c|c|c|c|}
\hline Parameter & Uninfected & $\begin{array}{l}\text { Infected } \\
\text { (PCR positive) }\end{array}$ & $P$ & $\begin{array}{l}\text { Microscopic } \\
\text { infection }\end{array}$ & $P$ & $\begin{array}{l}\text { Submicroscopic } \\
\text { infection }\end{array}$ & $P$ \\
\hline No. & 823 & 240 & & $148^{b}$ & & 100 & \\
\hline Anaemia (\%) & 29.6 & 60.4 & 0.0001 & 64.2 & 0.0001 & 52.0 & 0.0001 \\
\hline $\begin{array}{l}\mathrm{Hb}(\mathrm{g} / \mathrm{dL} ; \text { median, } \\
\text { range) }\end{array}$ & $12.6(7.1-16.6)$ & $11.6(6.0-15.1)$ & 0.0001 & $11.5(6.8-15.1)$ & 0.0001 & $11.9(6.0-14.5)$ & 0.0001 \\
\hline Current fever (\%) & 1.0 & 7.5 & 0.0001 & 10.8 & 0.0001 & 2.0 & 0.30 \\
\hline $\begin{array}{l}\text { Ax. Temperature }\left({ }^{\circ} \mathrm{C} ;\right. \\
\text { mean } \pm \mathrm{SD})\end{array}$ & $36.4 \pm 0.4$ & $36.6 \pm 0.8$ & 0.0001 & $36.7 \pm 0.9$ & 0.0001 & $36.5 \pm 0.5$ & 0.059 \\
\hline WAZ (SD; median, range) & $-0.98(-3.87-2.02)$ & $-1.25(-4.51-2.02)$ & 0.001 & $-1.40(-4.51-2.02)$ & 0.0001 & $-1.00(-3.44-0.42)$ & 0.93 \\
\hline $\begin{array}{l}\text { Underweight } \\
\quad(\text { WAZ }<-2 \text { SD, \%) }\end{array}$ & 14.1 & 20.8 & 0.045 & 27.0 & 0.0001 & 14.0 & 0.92 \\
\hline $\operatorname{MUAC}(\mathrm{cm} ; \text { mean } \pm \mathrm{SD})^{\mathrm{c}}$ & $16.3 \pm 1.3$ & $15.9 \pm 1.1$ & $<0.0001$ & $15.9 \pm 1.2$ & 0.0002 & $15.9 \pm 1.0$ & 0.007 \\
\hline $\begin{array}{l}\text { Clinically assessed mal- } \\
\text { nutrition (\%) }\end{array}$ & 19.8 & 28.3 & 0.005 & 35.1 & 0.0001 & 21.0 & 0.67 \\
\hline \multicolumn{8}{|c|}{ History within preceding 2 weeks (\%) } \\
\hline Fever & 19.8 & 45.0 & 0.0001 & 46.6 & 0.0001 & 41.0 & 0.0001 \\
\hline Tiredness & 10.6 & 24.2 & 0.0001 & 25.0 & 0.0001 & 23.0 & 0.0001 \\
\hline Vomiting & 6.6 & 14.6 & 0.0001 & 14.9 & 0.0001 & 14.0 & 0.0001 \\
\hline Abdominal pain & 30.3 & 45.8 & 0.001 & 48.6 & 0.0001 & 40.0 & 0.088 \\
\hline Poor appetite & 17.6 & 27.1 & 0.023 & 25.0 & 0.122 & 30.0 & 0.006 \\
\hline Weakness $^{\mathrm{a}}$ & 14.8 & 25.1 & 0.006 & 23.9 & 0.018 & 26.8 & 0.003 \\
\hline
\end{tabular}

Comparisons ( $P$ values) with uninfected group take into account cluster effects

a $n=1019$

b Eight children without confirmation by PCR

c $n=925$ 
of curative services. Anti-malarial treatment, mostly with artemether-lumefantrine, within the preceding month was paradoxically associated with increased infection prevalence. This observation was also made among children under 5 years of age in the study area [18] and may stem from recurring parasitaemia following treatment. Drug resistance markers associated with reappearing parasitaemia following artemether-lumefantrine treatment are established in the study area [33, 34], but reports on actual treatment failure are absent. No information on the completeness of treatment was collected, i.e., on adherence to the 3-days regimen, but incomplete drug intake, e.g., in the community or after the first dose in a health facility, may have contributed to reappearing parasitaemia. Moreover, persisting gametocytes could have produced positive PCR results. Alternatively, this finding may reflect the aggregation of infections including rapid re-infections in a specifically vulnerable subset of the population [35].

Recent studies on malaria parasitaemia among schoolage children have shown a prevalence range of $<1$ to $64 \%$ in East Africa and of 1 to $83 \%$ in West Africa [5]. Symptomatic malaria contributes to school absenteeism, impaired cognition and reduced school performance $[5,10,16,20]$. As for asymptomatic parasitaemia, predominating in the present study, findings are less clearcut: in Yemen [6] and DR Congo [36], no influence on children's cognition was observed while this was the case in Uganda [10], Mali [16], and Kenya [9]. Overall, asymptomatic parasitaemia is abundant; it accounts for three in four infections detected in community settings [4], and many of those are submicroscopic $[2,3]$. While some of these infections become symptomatic, most can remain asymptomatic for several months $[37,38]$. Counterintuitively, the proportion of submicroscopic infections on a global scale is inversely correlated to transmission intensity, i.e., the proportion is highest at low endemicity [2, $3,11,21]$. Asymptomatic carriers to a sizeable extent contribute to malaria transmission, also in low endemicity settings $[2,3,7]$, even though the magnitude of this impact is not well established [39]. In the present study, more than $90 \%$ of Plasmodium infected children attending school were considered asymptomatic based on the absence of fever. Nevertheless, anaemia prevalence was doubled in infected children and mean $\mathrm{Hb}$ reduced by $1 \mathrm{~g} / \mathrm{dL}$. This degree of $\mathrm{Hb}$ reduction is approximately half of that observed among younger and also largely asymptomatic children below 5 years in the study area [18]. In addition, infected children more frequently had underweight and clinically assessed malnutrition than their non-infected peers. These findings argue against asymptomatic presentation but rather for a less obvious one. This is even more the case when considering the more frequently positive histories in infected as compared to non-infected children of fever, tiredness, weakness, poor appetite, abdominal pain, and vomiting. The influence of submicroscopic infections on the latter was similar to the one of microscopically visible parasitaemia but the effect on $\mathrm{Hb}$ levels was smaller and no association with underweight was observed. These findings add to the notion that "asymptomatic" Plasmodium infections do have subtle health consequences and should be regarded as potentially harmful [15]. In fact, symptomless children infected with malaria parasites have been shown to have low-grade inflammation as well as evidence of platelet and endothelial activation, in addition to reduced $\mathrm{Hb} \mathrm{lev-}$ els [15].

The present study has limitations. The definition of asymptomatic was based on a single-time point assessment; potentially, some children were in a presymptomatic period of parasitaemia at the moment of examination. Likewise, PCR detection of malaria parasites may include gametocytes, e.g., persisting after treatment. Submicroscopic parasitaemia may reflect both, very early and thus asymptomatic infections, which later on could develop to clinical malaria, and low level infections persisting in individuals able to control parasitaemia. Of note, studies in murine models have demonstrated that plasmodial DNA is rapidly removed from circulation after treatment or inoculation of killed parasites [40]. Due to its design as a deworming study, questionnaire-based interviews focused on mainly general and gastrointestinal signs and symptoms whereas more intuitive malaria-related conditions, e.g., shivering or sweats, were not included. Although unfortunate, pronounced symptoms in this regard would likely have been detected upon clinical examination. Moreover, this circumstance enabled detecting significant associations of Plasmodium infection with less obvious "soft" symptoms. Plasmodium and Ascaris infections were not correlated and adjusting for the presence of the latter did not substantially affect the odds of symptoms due to the former. Infections with different Plasmodium species were combined since small numbers of non-falciparum malaria infections rendered separate analysis unsubstantial. In clinical terms, $P$. falciparum and $P$. ovale did not differ much, with the exception of a larger contribution to anaemia of the former.

The health and educational consequences of malaria and asymptomatic parasitaemia in school children as well as the role of this large group as a silent reservoir of infection are increasingly recognized [5, 9-20]. School children are not specifically targeted in malaria control programmes so far, and due to the predominance of seemingly asymptomatic parasitaemia, these infections usually remain untreated. The use of insecticide-treated 
nets (ITNs) in school children is notoriously low [5, 41] but schools are ideally suited to provide education on malaria, prevention and ITNs. This may include information on the importance of adhering to the 3-days regimen of artemisinin-based combination treatment. Schools also can serve as hubs for ITN distribution, and boarding schools in endemic areas should equip their dormitories with ITNs. Chemoprophylaxis or intermittent preventive treatment (IPT) have shown to reduce malaria-associated morbidity in school children [42, 43]. IPT, also termed intermittent parasite clearance in schools (IPCs) or seasonal malaria chemoprevention (SMC), needs to account for the epidemiological characteristics of malaria in a given area, and can greatly reduce the proportion of Plasmodium infected children (reviewed in Ref. [5]), and also improve sustained attention [9]. School-based intermittent screening and treatment of malaria is another option but results have been disappointing so far [44]. It remains to be elucidated, which drug-based regimen fits best and is most cost-effective for the different transmission settings across SSA. Integration with other school-based health promotion activities, e.g., routine deworming, is also desirable.

\section{Conclusion}

Morbidity due to Plasmodium infection even if asymptomatic at first sight, associated impaired educational performance $[5,10,16,20]$ and contribution to transmission $[2,3,7]$ argue for the inclusion of school children into improved surveillance and control activities.

\begin{abstract}
Authors' contributions
$J B G, C B, K C S$, and FPM designed the study. KCS, DG, CM, JCM, FH, KF, CB, JN, and FPM were responsible for patient recruitment, clinical and laboratory examinations. IU, CK, GSH, TA, and AS contributed to data interpretation. PM did the statistical analyses. KCS and FPM wrote the paper with major contributions of the other authors. All authors read and approved the final manuscript.
\end{abstract}

\section{Author details \\ ${ }^{1}$ Institute of Tropical Medicine and International Health, Charité-University Medicine Berlin, Berlin, Germany. ${ }^{2}$ University Teaching Hospital of Butare, Uni- versity of Rwanda, Butare, Rwanda. ${ }^{3}$ Institute for Parasitology and Tropical Vet- erinary Medicine, Freie Universität Berlin, Berlin, Germany. ${ }^{4}$ Malaria and Other Parasitic Diseases Division, Rwanda Biomedical Center, Kigali, Rwanda. ${ }^{5}$ Swiss Tropical and Public Health Institute, Basel, Switzerland. ${ }^{6}$ University of Basel, Basel, Switzerland. ${ }^{7}$ Mycotic and Parasitic Agents and Mycobacteria, Department of Infectious Diseases, Robert Koch-Institute, Berlin, Germany. ${ }^{8}$ Institute for Clinical Epidemiology and Applied Biometry, University Hospital, Tuebingen, Germany.}

\section{Acknowledgements}

We thank the participating pupils, parents, teachers, community health workers, and UTHB laboratory staff. This work forms part of the doctoral theses of $\mathrm{KCS}$ and DG.

\section{Competing interests}

The authors declare that they have no competing interests.

\section{Availability of data and material}

Data supporting the findings will be available upon request sent to the corresponding author.

\section{Ethics approval and consent to participate}

Written informed consent and assent were obtained from the parents and the children, respectively. The study protocol was approved by the Rwandan National Ethics Committee (242/RNEC/2014), and the Rwandan Ministry of Education granted permission to conduct the study (2543/12.00/2014).

\section{Funding}

This study was supported by the German Federal Ministry of Education and Research (Grant 01DG13006A, MOPACUR). The sponsor had no role in study design; in the collection, analysis and interpretation of data; in the writing of the report; or in the decision to submit the article for publication.

Received: 7 September 2016 Accepted: 7 November 2016

Published online: 14 November 2016

\section{References}

1. White NJ, Pukrittayakamee S, Hien TT, Faiz MA, Mokuolu OA, Dondorp AM. Malaria. Lancet. 2014;383:723-35.

2. Bousema T, Okell L, Felger I, Drakeley C. Asymptomatic malaria infections: detectability, transmissibility and public health relevance. Nat Rev Microbiol. 2014;12:833-40.

3. Galatas B, Bassat Q, Mayor A. Malaria parasites in the asymptomatic: looking for the hay in the haystack. Trends Parasitol. 2016;32:296-308.

4. Greenwood BM. Asymptomatic malaria infections-do they matter? Parasitol Today. 1987;3:206-14.

5. Nankabirwa J, Brooker SJ, Clarke SE, Fernando D, Gitonga CW, Schellenberg D, et al. Malaria in school-age children in Africa: an increasingly important challenge. Trop Med Int Health. 2014;19:1294-309.

6. Al Serouri AW, Grantham-McGregor SM, Greenwood B, Costello A. Impact of asymptomatic malaria parasitaemia on cognitive function and school achievement of schoolchildren in the Yemen Republic. Parasitology. 2000;121:337-45.

7. Alves FP, Gil LH, Marrelli MT, Ribolla PE, Camargo EP, Da Silva LH. Asymptomatic carriers of Plasmodium spp. as infection source for malaria vector mosquitoes in the Brazilian Amazon. J Med Entomol. 2005;42:777-9.

8. Baliraine FN, Afrane YA, Amenya DA, Bonizzoni M, Menge DM, Zhou G, et al. High prevalence of asymptomatic Plasmodium falciparum infections in a highland area of western Kenya: a cohort study. J Infect Dis. 2009;200:66-74.

9. Clarke SE, Jukes MC, Njagi JK, Khasakhala L, Cundill B, Otido J, et al. Effect of intermittent preventive treatment of malaria on health and education in schoolchildren: a cluster-randomised, double-blind, placebo-controlled trial. Lancet. 2008:372:127-38.

10. Nankabirwa J, Wandera B, Kiwanuka N, Staedke SG, Kamya MR, Brooker SJ. Asymptomatic Plasmodium infection and cognition among primary schoolchildren in a high malaria transmission setting in Uganda. Am J Trop Med Hyg. 2013;88:1102-8.

11. Okell LC, Bousema T, Griffin JT, Ouédraogo AL, Ghani AC, Drakeley CJ. Factors determining the occurrence of submicroscopic malaria infections and their relevance for control. Nat Commun. 2012;3:1237.

12. Kateera $F$, Mens $P F$, Hakizimana $E$, Ingabire $C M$, Muragijemariya $L$, Karinda P, et al. Malaria parasite carriage and risk determinants in a rural population: a malariometric survey in Rwanda. Malar J. 2015;14:16.

13. Laishram DD, Sutton PL, Nanda N, Sharma VL, Sobti RC, Carlton JM, et al. The complexities of malaria disease manifestations with a focus on asymptomatic malaria. Malar J. 2012;11:29.

14. Walldorf JA, Cohee LM, Coalson JE, Bauleni A, Nkanaunena K, KapitoTembo A, et al. School-age children are a reservoir of malaria infection in Malawi. PLoS ONE. 2015;10:e0134061.

15. de Mast Q, Brouwers J, Syafruddin D, Bousema T, Baidjoe AY, de Groot PG, et al. Is asymptomatic malaria really asymptomatic? Hematological, vascular and inflammatory effects of asymptomatic malaria parasitemia. J Infect. 2015;71:587-96.

16. Thuilliez J, Sissoko MS, Toure OB, Kamate P, Berthélemy JC, Doumbo OK. Malaria and primary education in Mali: a longitudinal study in the village of Donéguébougou. Soc Sci Med. 2010;71:324-34. 
17. Kurtzhals JA, Addae MM, Akanmori BD, Dunyo S, Koram KA, Appawu MA, et al. Anaemia caused by asymptomatic Plasmodium falciparum infection in semi-immune African schoolchildren. Trans R Soc Trop Med Hyg. 1999:93:623-7.

18. Gahutu JB, Steininger C, Shyirambere C, Zeile I, Cwinya-Ay N, Danquah I, et al. Prevalence and risk factors of malaria among children in southern highland Rwanda. Malar J. 2011;10:134.

19. Ehrhardt S, Burchard GD, Mantel C, Cramer JP, Kaiser S, Kubo M, et al. Malaria, anemia, and malnutrition in African children-defining intervention priorities. J Infect Dis. 2006;194:108-14.

20. Fernando SD, Rodrigo C, Rajapakse S. The 'hidden' burden of malaria: cognitive impairment following infection. Malar J. 2010;9:366.

21. Okell LC, Ghani AC, Lyons E, Drakeley CJ. Submicroscopic infection in Plasmodium falciparum-endemic populations: a systematic review and meta-analysis. J Infect Dis. 2009;200:1509-17.

22. Karema C, Aregawi MW, Rukundo A, Kabayiza A, Mulindahabi M, Fall IS, et al. Trends in malaria cases, hospital admissions and deaths following scale-up of anti-malarial interventions, 2000-2010, Rwanda. Malar J. 2012;11:236.

23. Staudacher $\mathrm{O}$, Heimer J, Steiner F, Kayonga Y, Havugimana JM, Ignatius $\mathrm{R}$, et al. Soil-transmitted helminths in southern highland Rwanda: associated factors and effectiveness of school-based preventive chemotherapy. Trop Med Int Health. 2014;19:812-24.

24. World Health Organization. WHO AnthroPlus software. Geneva: World Health Organization. 2009. http://www.who.int/growthref/tools/en/. Accessed 31 Oct 2016.

25. Sullivan KM, Mei Z, Grummer-Strawn L, Parvanta I. Haemoglobin adjustments to define anaemia. Trop Med Int Health. 2008;13:1267-71.

26. Rubio JM, Post RJ, van Leeuwen WM, Henry MC, Lindergard G, Hommel $M$. Alternative polymerase chain reaction method to identify Plasmodium species in human blood samples: the semi-nested multiplex malaria PCR (SnM-PCR). Trans R Soc Trop Med Hyg. 2002;96(Suppl 1):S199-204.

27. Basuni M, Muhi J, Othman N, Verweij JJ, Ahmad M, Miswan N, et al. A pentaplex real-time polymerase chain reaction assay for detection of four species of soil-transmitted helminths. Am J Trop Med Hyg. 2011;84:338-43.

28. Drakeley CJ, Carneiro I, Reyburn H, Malima R, Lusingu JP, Cox J, et al. Altitude-dependent and -independent variations in Plasmodium falciparum prevalence in northeastern Tanzania. J Infect Dis. 2005;191:1589-98.

29. Mboera LE, Kamugisha ML, Rumisha SF, Kisinza WN, Senkoro KP, Kitua AY. Malaria and mosquito net utilisation among schoolchildren in villages with or without healthcare facilities at different altitudes in Iringa District. Tanzania. Afr Health Sci. 2008;8:114-9.

30. Bødker R, Msangeni HA, Kisinza W, Lindsay SW. Relationship between the intensity of exposure to malaria parasites and infection in the Usambara Mountains, Tanzania. Am J Trop Med Hyg. 2006;74:716-23.
31. Protopopoff N, Van Bortel W, Marcotty T, Van Herp M, Maes P, Baza D, et al. Spatial targeted vector control in the highlands of Burundi and its impact on malaria transmission. Malar J. 2007;6:158.

32. Bizimana JP, Twarabamenye E, Kienberger S. Assessing the social vulnerability to malaria in Rwanda. Malar J. 2015;14:2.

33. Zeile I, Gahutu JB, Shyirambere C, Steininger C, Musemakweri A, Sebahungu $F$, et al. Molecular markers of Plasmodium falciparum drug resistance in southern highland Rwanda. Acta Trop. 2012;121:50-4.

34. Tacoli C, Gai PP, Bayingana C, Sifft K, Geus D, Ndoli J, et al. Artemisinin resistance-associated K13 polymorphisms of Plasmodium falciparum in southern Rwanda, 2010-2015. Am J Trop Med Hyg. 2016. doi:10.4269/ ajtmh.16-0483

35. Woolhouse ME, Dye C, Etard JF, Smith T, Charlwood JD, Garnett GP, et al. Heterogeneities in the transmission of infectious agents: implications for the design of control programs. Proc Natl Acad Sci USA. 1997;94:338-42.

36. Boivin MJ, Giordani B, Ndanga K, Maky MM, Manzeki KM, Ngunu N, et al. Effects of treatment for intestinal parasites and malaria on the cognitive abilities of schoolchildren in Zaire, Africa. Health Psychol. 1993;12:220-6.

37. Babiker HA, Abdel-Muhsin AM, Ranford-Cartwright LC, Satti G, Walliker D. Characteristics of Plasmodium falciparum parasites that survive the lengthy dry season in eastern Sudan where malaria transmission is markedly seasonal. Am J Trop Med Hyg. 1998;59:582-90.

38. Roucher C, Rogier C, Dieye-Ba F, Sokhna C, Tall A, Trape JF. Changing malaria epidemiology and diagnostic criteria for Plasmodium falciparum clinical malaria. PLoS ONE. 2012;7:e46188.

39. Lin JT, Ubalee R, Lon C, Balasubramanian S, Kuntawunginn W, Rahman R, et al. Microscopic Plasmodium falciparum gametocytemia and infectivity to mosquitoes in Cambodia. J Infect Dis. 2016;213:1491-4.

40. Jarra W, Snounou G. Only viable parasites are detected by PCR following clearance of rodent malarial infections by drug treatment or immune responses. Infect Immun. 1998;66:3783-7.

41. Noor AM, Kirui VC, Brooker SJ, Snow RW. The use of insecticide treated nets by age: implications for universal coverage in Africa. BMC Public Health. 2009;9:369.

42. Geerligs PD, Brabin BJ, Eggelte TA. Analysis of the effects of malaria chemoprophylaxis in children on haematological responses, morbidity and mortality. Bull World Health Organ. 2003;81:205-16.

43. Meremikwu MM, Donegan S, Esu E. Chemoprophylaxis and intermittent treatment for preventing malaria in children. Cochrane Database Syst Rev. 2008;2:CD003756.

44. Halliday KE, Okello G, Turner EL, Njagi K, Mcharo C, Kengo J, et al. Impact of intermittent screening and treatment for malaria among school children in Kenya: a cluster randomised trial. PLoS Med. 2014;11:e1001594.

\section{Submit your next manuscript to BioMed Central and we will help you at every step:}

- We accept pre-submission inquiries

- Our selector tool helps you to find the most relevant journal

- We provide round the clock customer support

- Convenient online submission

- Thorough peer review

- Inclusion in PubMed and all major indexing services

- Maximum visibility for your research

Submit your manuscript at www.biomedcentral.com/submit 